\title{
WELDING OF SINGLE CRYSTAL SUPERALLOY CMSX-4: EXPERIMENTS AND MODELING
}

\author{
D. Dye ${ }^{1}$, K.T. Conlon ${ }^{2}$, P.D. Lee ${ }^{1}$, R.B. Rogge ${ }^{2}$, R.C. Reed $^{3}$ \\ ${ }^{1}$ Department of Materials, Royal School of Mines, Imperial College, Prince Consort Road, South Kensington, \\ London SW7 2BP, UK \\ ${ }^{2}$ National Research Council of Canada, Chalk River Laboratories, Chalk River, Ontario K0J 1J0, Canada \\ ${ }^{3}$ Department of Materials and Metals Engineering, University of British Columbia, 309-6350 Stores Road, \\ Vancouver, BC V6T 1Z4, Canada
}

Keywords: CMSX-4, welding, residual stress, finite element method, neutron diffraction

\begin{abstract}
The residual stresses in a gas tungsten arc weld of the single crystal superalloy CMSX-4 have been examined using neutron diffraction techniques. The longitudinal component of the residual stress field was found to be dominant, reaching a value of $650 \mathrm{MPa}$ in the weld zone. In order to rationalise the results, finite element modeling was carried out. Strategies are suggested for the manufacture of a single crystal weld that is not subject to strain-induced recrystallization during heat treatment.
\end{abstract}

\section{Introduction}

With the current trend towards the use of single crystal castings for critical components in the gas turbine, e.g. for the turbine blades and nozzle guide vanes, there is an urgent need to develop welding procedures by which the parts might be processed without defects such as cracks and tears. This is particularly the case for blade repair, e.g. for the remediation of casting defects and the rehabilitation of blades that have been abraded in service, and for the filling of holes left in hollow blades from casting, Figure 1. Particularly for the large single crystals used in industrial gas turbines, where scrap is very expensive, a remediation technique would be of enormous benefit. A number of workers have been developing techniques for the welding and build-up of single crystals [1, 2, 3]. Unfortunately, the production of crack-free welds in superalloys is very challenging due to the large solidification range, which leads to a propensity for solidification cracking, and the significant creep resistance which prevent stresses from being relaxed during cooling. In this paper, neutron diffraction experiments are used to deduce the thermalmechanical strains and stresses induced by welding. To rationalize these data and the modes of cracking which occur, numerical modeling is employed.

The approach builds on recent work $[4,5]$ aimed at identifying and quantifying the factors which are relevant to the thermal-mechanical response of superalloys to welding, specifically the residual strains and the related patterns of distortion; it turns out that the way these evolve has a strong impact on whether a defect-free weld is produced. Unfortunately, whilst the neutron strain scanning technique is well established for polycrystalline alloys, it remains unproven for welds in single crystals. Previous work has focussed on characterizing the mosaic spread in industrial single crystal castings $[6,7]$ although a limited amount of work has been done on the loading behavior [8]. We believe that this paper contains the first reported neutron diffraction strain measurements on a weld in a single crystal superalloy. In fact, we have overcome significant experimental challenges which relate to the development of an appropriate technique; this is because for a single crystal the sample must be precisely aligned to place the diffraction spot on the detector. In order to verify that this approach yields reasonable results, we have made measurements of the loading behavior of the $\gamma^{\prime}$ phase in the (100) direction.

\section{Experimental Procedure}

The measurements were carried out on $50 \times 25 \times 2 \mathrm{~mm}$ rectilinear plates fabricated from a solution heat-treated test casting of CMSX-4. The plates were cut from a larger casting such that the long axis of the plate was aligned with the [100] growth direction and the other two axes were nominally aligned with the secondary [010] and [001] axes. A bead-on-plate hand weld was manufactured at a nominal power of $580 \mathrm{~W}$ and a welding speed of $1.5 \mathrm{~mm} \mathrm{~s}^{-1}$ using autogenous gas tungsten arc welding at the RollsRoyce facility in Bristol, England.

Neutron diffraction strain measurement relies upon the change in lattice spacing to infer the elastic strain in the material, in effect using the lattice expansion as a microscopic internal strain gauge. The strain $\varepsilon$ is obtained from the change in lattice spacing $d$ from a strain free reference 

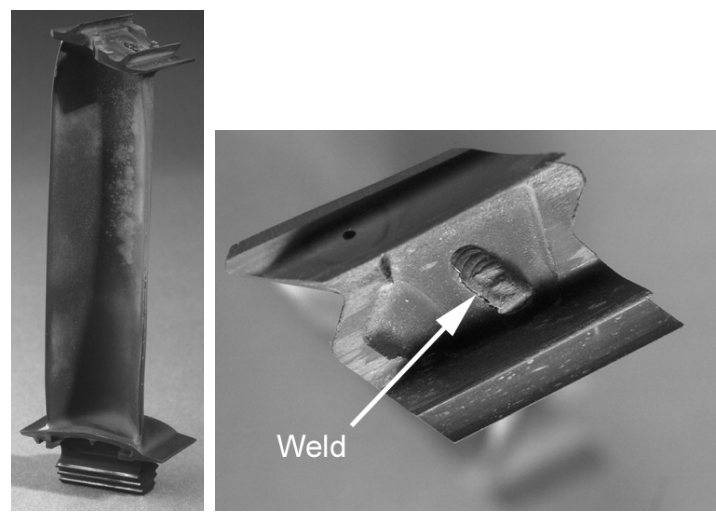

Figure 1: Single crystal superalloy turbine blade with a sealing filler weld in the shroud, filling the hole left by the ceramic casting insert.

$d_{0}$ via

$$
\varepsilon=\frac{\Delta d}{d_{0}}
$$

The neutron measurements were made using the L3 diffractometer at Atomic Energy of Canada's NRU reactor in Chalk River, ON, Canada. Measurements were made using neutron wavelengths of $1.5661 \AA$ for the (300) and (030) $\gamma^{\prime}$ peaks, obtained using the $\{115\}$ reflection from a Germanium monochromator. For measurements using the (330) $\gamma^{\prime}$ peak, a wavelength of $1.1398 \AA$ was used, obtained from the Ge\{117\}. The strain-free reference was obtained using a far-field measurement of the lattice parameter in the normal direction. The diffractometer arrangement is shown in Figure 2. The measurements were made using a sampling (gauge) volume of $1 \times 1 \times 1 \mathrm{~mm}$. The measured strains were converted to stress using literature data for the stiffness of the isolated $\gamma^{\prime}$ phase from Sieborger et al [9], shown in Table 1, assuming that the plate was in a condition of plane stress.

Care was taken to establish that the measurement technique used could measure strains in a single crystal reliably. In this experiment, the measurements were made using a multiwire detector, and the sample was oscillated by approximately $4^{\circ}$ during each measurement; the period of the oscillation was $\sim 1$ minute, and the measurements required 6 minutes per point. The rationale behind this approach was to obtain $d$-spacing measurements averaged over the entire mosaic spread of the dendrites contained within the gauge volume. Measurements were made using the $\gamma^{\prime}$ phase because, at a volume fraction of $>70 \%$, it is the majority phase.

In addition, measurements were made $^{1}$ on a CMSX-4 tensile testpiece of the loading behaviour of the $\gamma$ and $\gamma^{\prime}$

\footnotetext{
${ }^{1}$ Dye, Conlon, Rogge and Reed. Neutron diffraction characterization of load partitioning in CMSX-4, in preparation for submission to Acta Materialia.
}

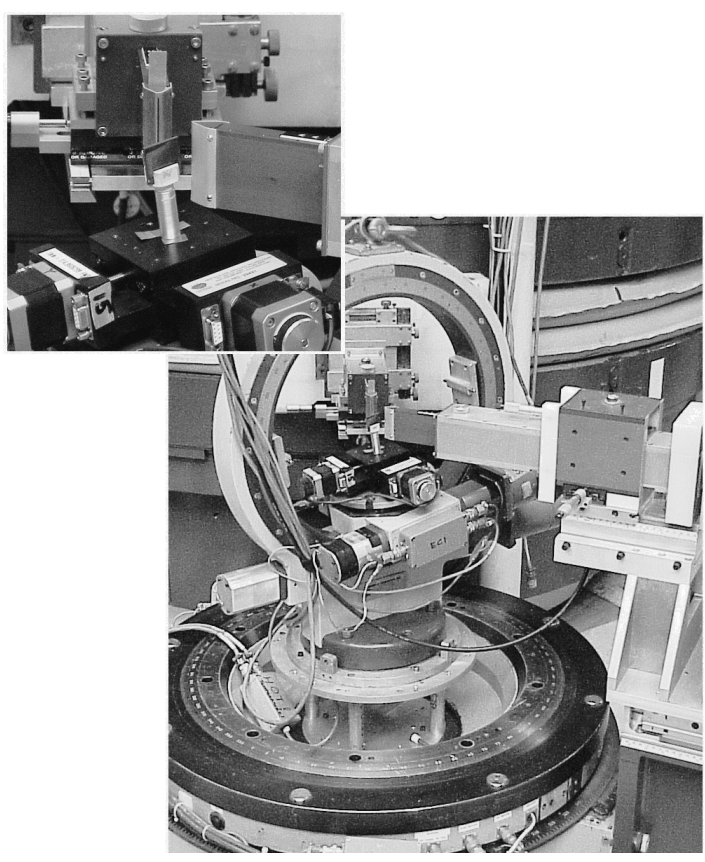

Figure 2: Illustration of the diffractometer arrangement. The specimen is placed on a 3 -axis linear stage inside an Eulerian Cradle.

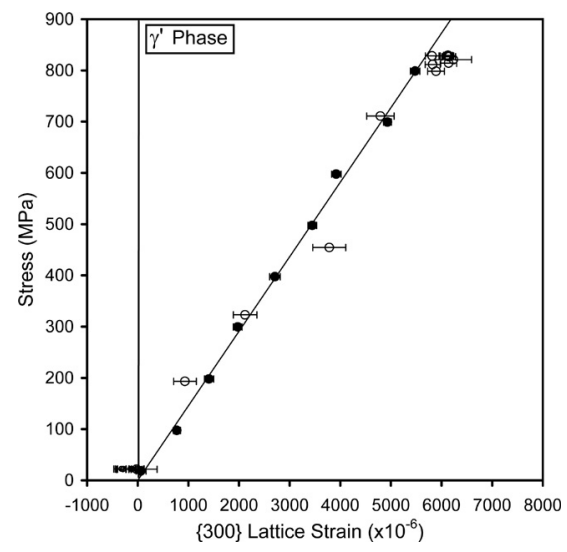

Figure 3: Measured lattice strains obtained during roomtemperature tensile testing of CMSX-4 in the $\gamma^{\prime}$ phase using the measurement approach taken here to measure residual strains in a component. The plastic strain applied was $5 \%$.

\begin{tabular}{ccc}
\hline$E$ & $G$ & $\nu$ \\
$(\mathrm{GPa})$ & $(\mathrm{GPa})$ & $(-)$ \\
\hline 127 & 144 & 0.39 \\
\hline
\end{tabular}

Table 1: Stiffness constants used for the $\gamma^{\prime}$ for conversion of the measured strains to stress. 


\begin{tabular}{|c|c|c|c|c|c|c|c|c|c|}
\hline $\begin{array}{c}\text { Temp. } \\
T \\
\left({ }^{\circ} \mathrm{C}\right) \\
\text { ref. }\end{array}$ & $\begin{array}{c}\text { Thermal } \\
\text { Conductivity } \\
\kappa \\
\left(\mathrm{W} \mathrm{m}^{-1} \mathrm{~K}^{-1}\right) \\
{[10]}\end{array}$ & $\begin{array}{c}\text { Density } \\
\rho \\
\left(\mathrm{kg} \mathrm{m}^{-3}\right) \\
{[10]}\end{array}$ & $\begin{array}{c}\text { Specific Heat } \\
\text { Capacity } \\
C_{p} \\
\left(\mathrm{~J} \mathrm{~kg}^{-1} \mathrm{~K}^{-1}\right) \\
{[10]} \\
10]\end{array}$ & $\begin{array}{c}\text { Young's } \\
\text { Modulus } \\
\text { along }(x 00) \\
(\mathrm{GPa}) \\
{[9]}\end{array}$ & $\begin{array}{c}\text { Shear } \\
\text { Modulus } \\
\text { (GPa) } \\
{[9]}\end{array}$ & $\begin{array}{c}\text { Poisson's } \\
\text { ratio } \\
\nu \\
(-) \\
{[9]} \\
\end{array}$ & $\begin{array}{c}\text { Mean Thermal } \\
\text { Expansion } \\
\text { Coefficient } \alpha \\
\left(\times 10^{-6}\right) \\
{[11]}\end{array}$ & $\begin{array}{c}\text { Yield } \\
\text { Stress } \\
\left(\varepsilon_{p l}=0\right) \\
(\mathrm{MPa}) \\
{[12]}\end{array}$ & $\begin{array}{c}\text { Yield } \\
\text { Stress } \\
\left(\varepsilon_{p l}=5 \%\right) \\
(\mathrm{MPa}) \\
{[12]}\end{array}$ \\
\hline 20 & 8.65 & 8700 & 397 & 127.3 & 131.3 & 0.389 & 11.1 & 385.0 & 411.0 \\
\hline 100 & 8.65 & 8665 & 415 & 125.0 & 128.7 & 0.391 & 11.8 & 384.0 & 409.0 \\
\hline 200 & 10.1 & 8618 & 431 & 122.0 & 125.5 & 0.394 & 12.8 & 383.0 & 408.0 \\
\hline 300 & 11.6 & 8572 & 445 & 118.0 & 121.9 & 0.395 & 13.7 & 382.0 & 406.0 \\
\hline 400 & 13.4 & 8525 & 456 & 115.0 & 118.6 & 0.395 & 14.7 & 381.0 & 404.0 \\
\hline 500 & 14.9 & 8479 & 466 & 111.0 & 114.3 & 0.395 & 15.6 & 380.0 & 402.0 \\
\hline 600 & 16.8 & 8433 & 488 & 106.0 & 109.9 & 0.396 & 16.5 & 383.0 & 405.0 \\
\hline 700 & 19.4 & 8387 & 532 & 101.0 & 107.1 & 0.398 & 17.4 & 406.0 & 427.0 \\
\hline 800 & 20.6 & 8342 & 530 & 96.0 & 102.3 & 0.403 & 18.3 & 446.0 & 466.0 \\
\hline 900 & 21.8 & 8296 & 540 & 90.2 & 99.0 & 0.41 & 19.2 & 346.0 & 365.0 \\
\hline 1000 & 22.3 & 8251 & 550 & 82.7 & 93.7 & 0.42 & 20.1 & 269.0 & 286.0 \\
\hline 1100 & 23.9 & 8206 & 560 & 75.1 & 88.3 & 0.43 & 21.0 & 165.0 & 181.0 \\
\hline 1200 & 25.8 & 8161 & 570 & 67.6 & 82.9 & 0.44 & 21.8 & 63.7 & 77.5 \\
\hline 1300 & 27.2 & 8116 & 580 & 60.1 & 77.5 & 0.45 & 22.7 & 27.6 & 39.9 \\
\hline 1320 & 27.2 & 8107 & 580 & 58.6 & 76.4 & 0.452 & 19.5 & 20.4 & 32.4 \\
\hline 1380 & 35.0 & 7754 & 675 & 54.0 & 73.2 & 0.458 & 18.6 & 20.4 & 31.4 \\
\hline 2000 & 35.0 & 7754 & 675 & 54.0 & 73.2 & 0.458 & 12.9 & 20.4 & 31.4 \\
\hline
\end{tabular}

Table 2: Temperature-dependent thermal and mechanical properties used in the finite element modeling. The thermal expansion $\varepsilon_{t h}$ is defined as the total expansion divided by the temperature, $\varepsilon_{t h}=\alpha T$, not the instantaneous expansion $\alpha=d \varepsilon_{t h} / d T$.

phases in the [100] direction. These showed that only minimal microstrains, that is, residual accommodation strains between the two phases, accumulated during plastic deformation and that linear loading behaviour could be obtained during a tensile test, Figure 3 . These results demonstrate that strain measurements can be made in a component of CMSX-4 that has undergone plastic deformation with a high degree of reliability. The diffraction elastic constant obtained from the loading measurement was not used instead of the literature data for the isolated $\gamma^{\prime}$ phase, because for the conversion to stress reported here both the shear modulus $G$ and Poisson's ratio $\nu$ are required as well as the Young's Modulus $E$ obtained experimentally.

\section{Numerical Model}

A sequentially coupled thermal-mechanical model was implemented in the finite element code Abaqus ${ }^{2}$. The model applied a constant-flux disc heat source $4 \mathrm{~mm}$ in width with a power of $320 \mathrm{~W}$, assuming a weld thermal efficiency of $55 \%$, established from previous work [4]. The velocity was ramped during welding from $1 \mathrm{~mm} \mathrm{~s}^{-1}$ to $2.1 \mathrm{~mm} \mathrm{~s}^{-1}$ to reproduce the reduction in weld pool width observed in the weld. In addition, the heat source was offset $1 \mathrm{~mm}$ from the weld centerline to match the welded plate.

\footnotetext{
${ }^{2}$ Abaqus/Standard, HKS Inc., Pawtucket, RI
}

Appropriate temperature-dependant materials properties derived from the literature were applied, which accounted for the anisotropy in the elastic constants and yield behavior. The properties used are shown in Table 2 . In line with the literature [13], a linear isotropic hardening model was used, using Hill's modification of the Von Mises criterion to model the anisotropy of yielding. This gives the yield criterion as

$$
\begin{aligned}
f^{2}(\sigma)=F\left(\sigma_{22}-\sigma_{33}\right) & +G\left(\sigma_{33}-\sigma_{11}\right)+H\left(\sigma_{11}-\sigma_{22}\right) \\
& +2 L \sigma_{23}+2 M \sigma_{31}+2 N \sigma_{12}
\end{aligned}
$$

where the $\sigma_{i j}$ are the stresses, and the parameters F, G,H and L,M,N are cyclic permutations of

$$
F=\frac{1}{2}\left(\frac{1}{R_{22}^{2}}+\frac{1}{R_{33}^{2}}-\frac{1}{R_{11}^{2}}\right) \quad L=\frac{3}{2 R_{23}^{2}}
$$

The parameters $R_{i i}$ and $R_{i j}$ were defined as 2.45 and 4.24 , respectively. Therefore the values given in Table 2 are the yield stresses for a uniaxial tensile test, divided by 2.45 .

It should be noted that this approach assumes that the temperature dependence of the yield curve does not depend on the kinetics of solute precipitation and takes no account of, for example, coarsening of the $\gamma^{\prime}$ precipitates, which is known to have a strong effect on the yield strength of nickel-base superalloys [14]. However, at the quench rates occurring during welding, we do not expect such age-induced hardening to be an important effect. 
(a)

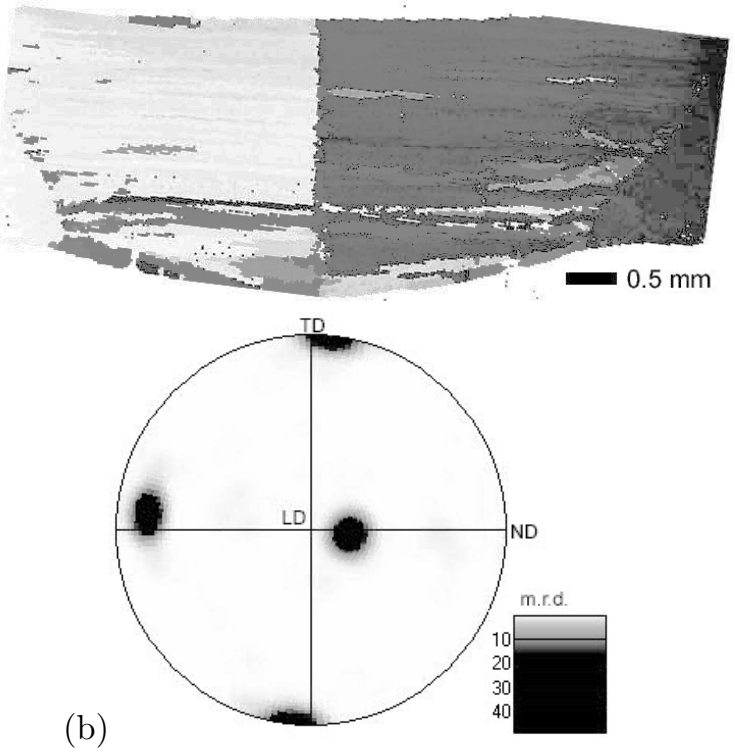

Figure 4: Electron backscatter diffraction image of the grain orientation distribution (a) and pole figure (b) illustrating the slight misorientation of the weld from the sample axes. TD is the normal direction in the sample, and ND is the transverse direction.

The mesh treated a $2 \mathrm{~mm}$ thick, $50 \mathrm{~mm}$ long and $12.5 \mathrm{~mm}$ wide section of the plate, using an element length of $0.625 \mathrm{~mm}$ in the axis of the plate with a thickness of $0.5 \mathrm{~mm}$; therefore the model contained 6,400 elements. Linear hexahedral elements were used for the thermal analysis (type DC3D8) and linear elements with enhanced bending modes for the mechanical analysis (type C3D8I). Compatibility of the temperature field with the displacement field in the mechanical model was guaranteed using the interpolation routine incorporated into ABAQUS, as discussed in previous work [4].

\section{Results and Discussion}

The weld showed a strong propensity for transverse solidification cracking, Figure 5(a). Cracking appears to have initiated at a grain boundary, and the crack has deflected around the primary dendrite arms, Figures $5(\mathrm{~b}-\mathrm{c})$. The evidence of solidified liquid around the broken primary dendrite arms indicates that cracking occurred before solidification was complete. This interpretation is reinforced by the observation that crack growth arrested at the edge of the fusion zone, Figure 5(d).

It was observed during the neutron experimentation that measurements could be made in the fusion zone at the same orientation as the parent plate, indicating that the majority of the weld metal was close to epitaxial with the base metal. An EBSD grain map and pole figure are shown in Figure 4, which indicate that the majority of

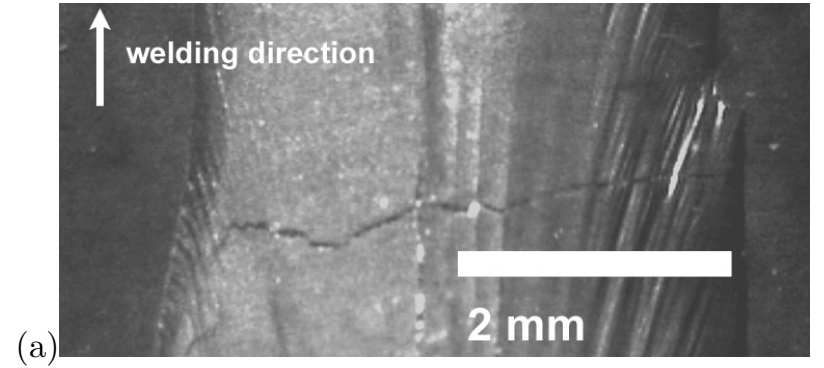

(b)

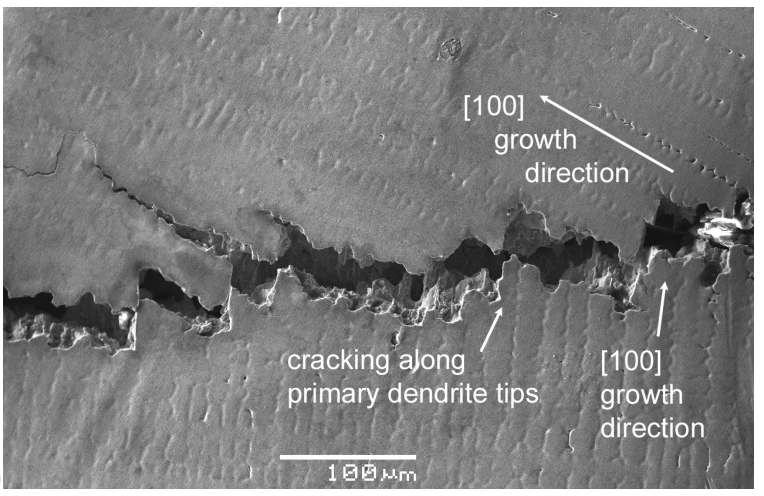

(c)

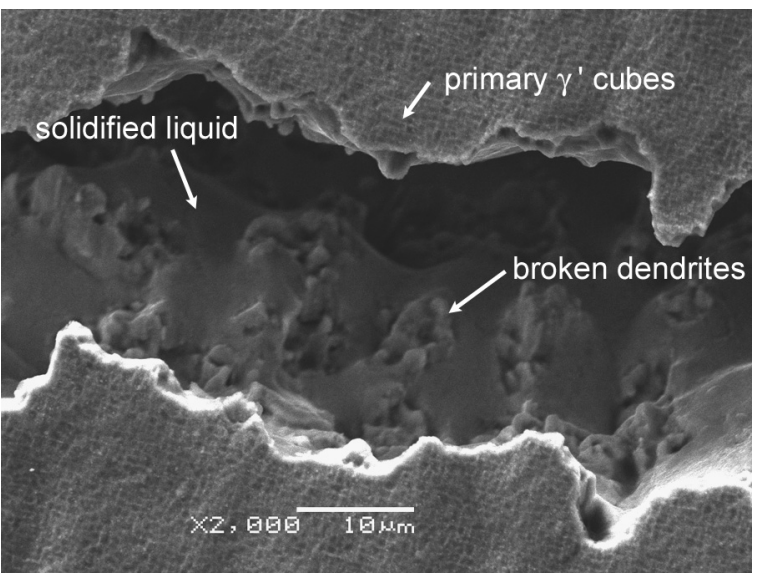

(d)

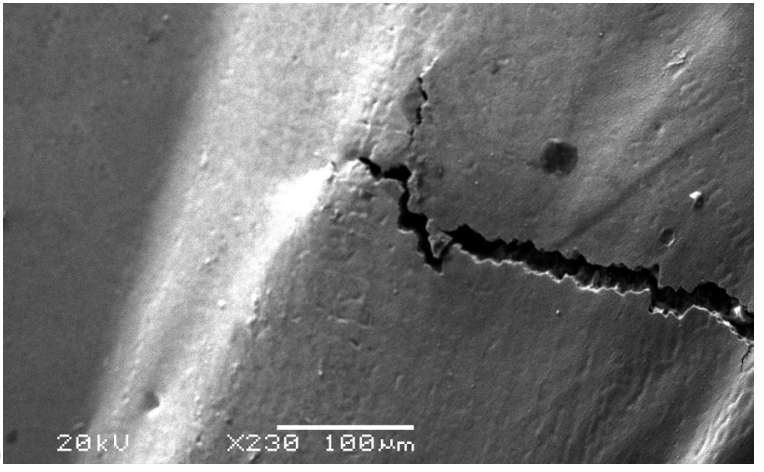

Figure 5: Macrograph (a) and scanning electron micrographs (b-d) of the transverse solidification crack in the weld. 
the weld zone is composed of grains well aligned with the parent crystal, but that in the bottom of the weld additional grains were nucleated which were subsequently cut off by grain selection during solidification. The low-angle $\left(2^{\circ}\right)$ grain boundary observed at the centreline is a consequence of both a misorientation between the two sides of the weld and also a sharp spike in misorientation across the weld centreline, at the final point of freezing. Thus in this case the goal of achieving a perfect single crystal weld was not attained, even though good alignment, as inferred from the neutron measurements, was achieved in the majority of the weld volume.

\section{Stress Measurements and Model Comparison}

At the mid-length of the plate and away from the surface-breaking crack, the measured longitudinal residual stresses were found to be tensile in the weld zone and of magnitude $\sim 650 \mathrm{MPa}$. The tensile region was $10 \mathrm{~mm}$ wide, which was greater than the weld zone width $(6 \mathrm{~mm})$. It was surrounded by a region which is up to $\sim 600 \mathrm{MPa}$ in compression. It was found that the measured transverse stresses are smaller and tensile, $<250 \mathrm{MPa}$, and were also tensile in the weld zone. The measured stresses are compared to the model results in Figure 6.

The measurements on the right-hand side of Figure 6 show a pronounced rise in the longitudinal and transverse stress and a corresponding drop in the shear stress. It is believed that this is an artifact either of the non-centering of the weld on the plate or of translation of the gauge volume towards the surface of the plate due to distortion of the welded plate. In the model, significant variations are observed in the stress state through-thickness; in Figure 6 the stresses at mid-depth are shown.

In the model, the longitudinal stresses are predicted to be tensile and of magnitude $\sim 800 \mathrm{MPa}$, with a tensile zone width of $10 \mathrm{~mm}$. In the far-field, compressive stresses are predicted, decreasing continuously to $-750 \mathrm{MPa}$ at the edge of the plate. The change in gradient in the compressive stresses in the far-field is associated with the edge of the plastic zone. Overall, the longitudinal stresses are in reasonable agreement with the measurements, except that the maximum tensile stress in the weld is slightly overpredicted, and the change in gradient at the edge of the plastic zone occurs slightly too close to the weld centerline and at slightly too high a stress.

The predicted transverse stresses are compressive in the weld region and smaller in magnitude than the longitudinal stresses, approx. $200 \mathrm{MPa}$, and increase to zero at the edge of the plate. A change in gradient is also observed at the edge of the plastic zone. The compressive stresses at the mid-length are balanced by tensile regions at the ends of the plate. In comparison to the measurements, then there is clearly some discrepancy. Excluding the right-hand edge, the transverse stresses are slightly
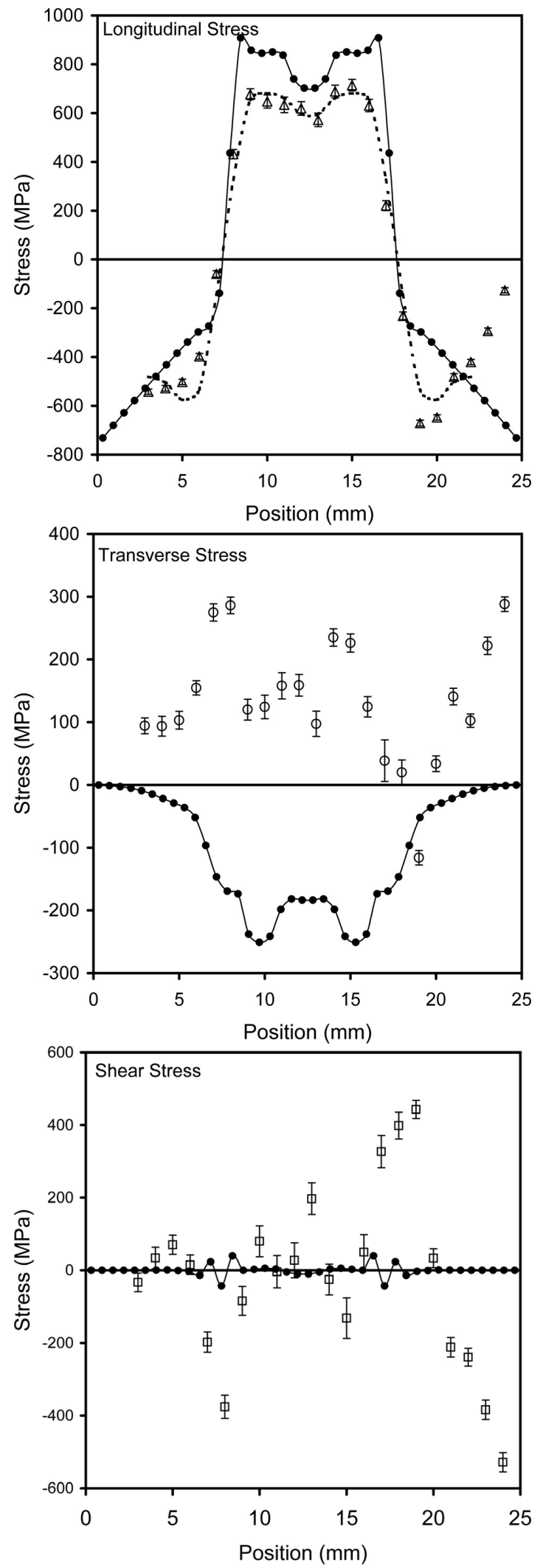

Figure 6: Predicted and measured residual stresses in the plate at mid-length. The solid lines and symbols are the model predictions, and the open symbols are the measured stresses. 
positive and in the range $80-250 \mathrm{MPa}$. This may be an effect produced by difference between the measurement location used, which was placed towards the end of the weld to avoid any stress relief due to cracking, and the model location, which was placed at mid-length. Since the minima in transverse stress and maxima in the longitudinal stress occur at the mid-length location, this discrepancy in the location examined could explain both the over-prediction of the longitudinal stresses and the under-prediction of the transverse stresses.

The in-plane shear stresses were found to be small. In the model, non-zero shear stresses are predicted only at the edge of the fusion zone, which is consistent with the majority of the measurements.

The residual stress state in the weld is broadly reproduced, which provides confidence that the model can be used to address the stress state around the weld pool that leads to cracking during welding.

\section{Avoidance of Cracking in Single Crystal Welds}

The transient longitudinal stress evolution predicted by the model is shown in Figure 7 , both in the fully solid state up to $1250{ }^{\circ} \mathrm{C}$ and in the partially liquid state between 1250 and $1380^{\circ} \mathrm{C}$. The fraction solid has been estimated using the Gulliver-Scheil approach and the thermodynamic software JMatPro ${ }^{3}$. It should be noted that the model treats the weld pool as a 'soft solid' with nominal mechanical properties and that this approach may be less than ideal for predicting the stresses during solidification. Nevertheless, the results indicate that during initial heating constrained thermal expansion causes compressive stresses to arise, which then increase towards zero as the material softens. As the material solidifies, contraction produces tensile stresses in the weld until the delayed heating of the heat affected zone produces a compressive effect. Finally the compressive plastic strains caused during heating result in a final tensile residual stress.

This pattern is also reproduced in Figure 8, which shows the transient state of stress of the plate top surface during welding. Again, compressive stresses are produced in front of the weld pool and ahead and to the side of the pool. These result in compressive plastic strains being produced and an in-plane shrinking of the material. In the immediate vicinity of the weld, the stresses are lower because of thermal softening but as solidification finishes tensile stresses are produced to balance the compressive plastic strains in the heat-affected zone. These then increase during cool-down of the weld.

This evolution, particularly the tensile longitudinal stresses predicted during solidification, is consistent with the appearance of transverse solidification cracks in the weld. This fact, taken with the predictions and experiments for the longitudinal stresses, confirms that the

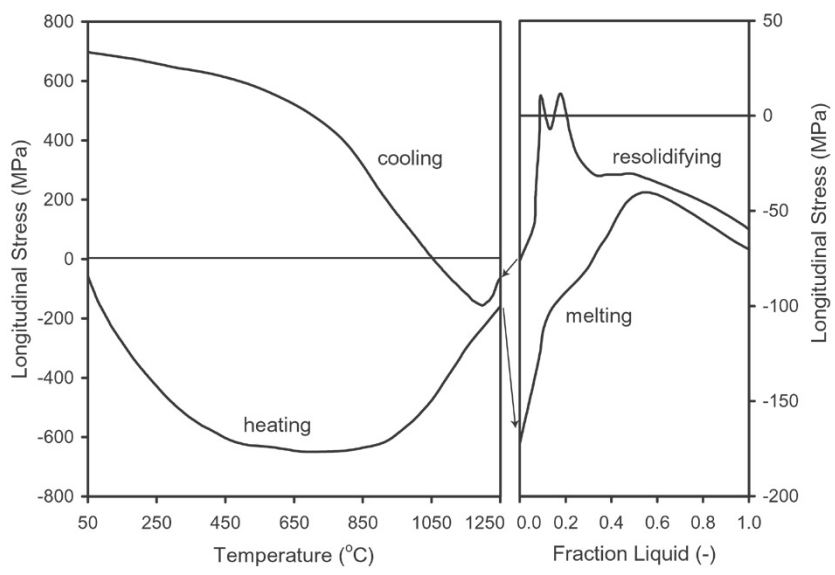

Figure 7: Predicted evolution of the longitudinal residual stress at the weld centerline, during heating (left graph), during melting and resolidification (right graph), and finally during cool-down (left graph).

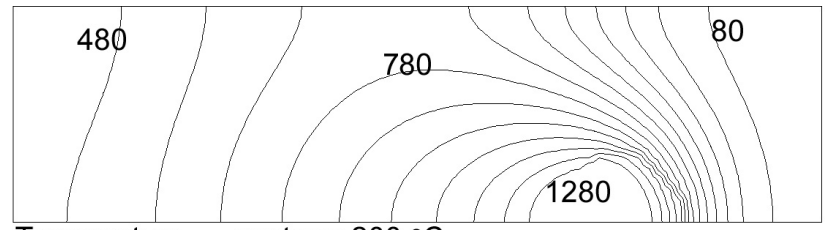

Temperature contour: $200^{\circ} \mathrm{C}$

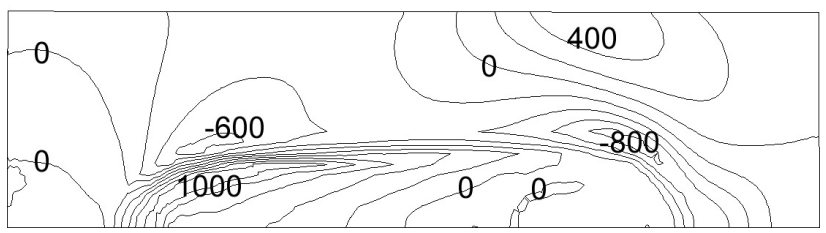

Longitudinal Stress contour: $200 \mathrm{MPa}$

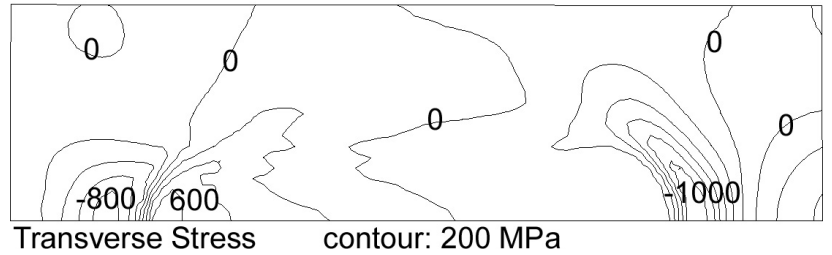

Figure 8: Predicted transient temperature and stress after $20 \mathrm{~s}, 85 \%$ of the way through the weld pass. $1380^{\circ} \mathrm{C}$ is the nominal liquidus predicted by JMatPro for CMSX-4.

\footnotetext{
${ }^{3}$ JMatPro, Sente Software Ltd., Guildford, UK
} 
modeling approach is useful in characterizing the thermalmechanical stresses which cause cracking to occur.

The microscopic observations suggest that if the nucleation of stray grains can be avoided, then weld cracking can be suppressed, since cracks are only observed at grain boundaries. In effect, this implies that the primary dendrite stems are strong enough to resist deformation without breaking off. This suggests that welding at a lower welding speed, which might be expected to produce greater stresses, would result in a more crack-resistant weld since stray grain nucleation is reduced at lower casting speeds.

The present weld was manufactured using no preheating of the plate; if preheating was used, then this would reduce the mechanical driving force for cracking, by reducing the thermal strain mismatch between the base metal and the weld. Therefore we also suggest that preheating be used to reduce cracking propensity. Of course, this will have the detrimental effect of reducing the thermal gradient around the weld since there will be less of a cooling sink, and therefore this will have a detrimental effect on the single-crystal dendrite growth problem. However, if recrystallization during homogenization heat treatment is to be avoided, then the residual stresses must be reduced. These competing effects suggest that it would be desirable for the model for stress and thermal evolution be coupled to a solidification model for the weld pool.

\section{Conclusions}

The following conclusions can be drawn from this work:

1. The residual stresses present were dominated by the longitudinal stress, which was up to $650 \mathrm{MPa}$ in the weld zone. The stresses were reproduced by a finite element model with reasonable accuracy.

2. Weld cracking was observed at the grain boundaries present in the weld. Electron Backscatter Diffraction showed that some grains in new orientations were nucleated at the fusion zone interface, even though the majority of the weld was well aligned with the parent plate.

3. It is suggested that in order to manufacture a single crystal weld that is not subject to strain-induced recrystallization during heat treatment then (i) the welding speed should be reduced to a speed closer to that used in investment casting, and (ii) that preheating be used to reduce the mechanical driving force for cracking and plasticity.

\section{Acknowledgements}

We gratefully acknowledge the provision of materials and assistance with manufacturing the weld provided by RollsRoyce plc., Bristol, UK. David Dye would also like to acknowledge the provision of a Visiting Fellowship at Chalk River by the National Science and Engineering Research Council (NSERC) of Canada.

\section{References}

[1] M. Gaümann, S. Henry, F. Cléton, J.-D Wagnière and W. Kurz, "Epitaxial laser metal forming: Analysis of microstructure formation", Mater. Sci. Engg. A, A271 (1999), 232-241.

[2] M. Gaümann, C. Bezençon, P. Canalis and W. Kurz, "Single-crystal laser deposition of superalloys: Processing-microstructure maps", Acta mater., 49 (2001), 1051-1062.

[3] J.-W. Park, S.S. Babu, J.M. Vitek, E.A. Kenik and S.A. David, "Stray grain formation in single crystal Nibase superalloy welds", J. Appl. Phys. 94(6) (2003), 42034209 .

[4] D. Dye, S. M. Roberts and R. C. Reed, "Modelling of the mechanical effects induced by the TIG welding of the IN718 superalloy", Metall. Trans. A, 32A(7) (2001), 1713-1725.

[5] M.V.R.S. Jensen, D. Dye, K.E. James, A.M. Korsunsky, S. M. Roberts and R. C. Reed, "Residual stresses in a welded superalloy disc: Characterization using synchrotron diffraction and numerical process modeling", Metall. Trans. A, 33A(9) (2002), 2921-2931.

[6] U. Glatzel and A. Müller, "Neutron scattering experiments with a nickel base superalloy Part I: Material and experiment", Scripta Metall. Mater., 31(3) (1994), 285290.

[7] U. Glatzel, "Neutron scattering experiments with a nickel base superalloy Part II: Analysis of intensity profiles", Scripta Metall. Mater., 31(3) (1994), 291-296.

[8] W. Reimers, "Analysis of residual stress states in coarse grained and single crystal nickel-base superalloys", $A d$ vances in X-Ray Analysis, 39 (1997), 211-223.

[9] D. Siebörger, H. Knake and U. Glatzel, "Temperature dependence of the elastic moduli of the nickel-base superalloy CMSX-4 and its isolated phases", Mater. Sci. Engg. A, A298(1-2) (2001), 26-33.

[10] K.C. Mills, Recommended values of thermophysical properties for selected commercial alloys, (Materials Park, OH: ASM Int'l, 2002).

[11] D.A. Grose and G.S. Ansell, "The influence of coherency strain on the elevated-temperature behavious of Ni-15CrAl-Ti-Mo alloys", Metall. Trans. A, 12A(9) (1981), 16311645 .

[12] A. Sengupta, S.K. Putatunda, L. Bartosieqicz, J. Hangas, P.J. Nailos, M.Peputapeck and F.E. Alberts, "Tensile behaviour of a new single crystal superalloy (CMSX-4) at room and elevated temperatures", J. Mater. Engg. Performance, 3(5) (1994), 664-672.

[13] J. Goldak, M. Bibby, J. Moore, R. House and B. Patel, "Computer modelling of heat flow in welds", Metall. Trans. B, 17B (1986), 587-600.

[14] M. P. Jackson and R. C. Reed, "Heat treatment of U720Li: The effect of microstructure on properties" Mater. Sci. Engg. A, 259A (1999), 85-97. 
